Tohoku J. Exp. Med., 2004, 202, 203-211

\title{
Significance of Post-Exercise Increment of Urinary Bicarbonate and pH in Subjects Loaded with Submaximal Cycling Exercise
}

\author{
Tetsushi Moriguchi, Akio Tomoda, ${ }^{1}$ Shiro Ichimura, Yuko Odagiri, \\ Shigeru Inoue, Takeshi Nagasawa, Hiroshi Tanaka, ${ }^{2}$ Naoki Nakagawa and \\ TerUichi SHIMOMITSU \\ Department of Preventive Medicine and Public Health, ${ }^{1}$ Department of Bio- \\ chemistry, Tokyo Medical University, Tokyo 160-8402, and \\ ${ }^{2}$ Department of Foreign Language (Physical Education), Daito Bunka Univer- \\ sity, Tokyo 175-0082
}

Moriguchi, T., Tomoda, A., Ichimura, S., Odagiri, Y., Inoue, S., Nagasawa, T., Tanaka, H., Nakagawa, N. and Shimomitsu, T. Significance of Post-Exercise Increment of Urinary Bicarbonate and $\mathrm{pH}$ in the Subjects Loaded with Submaximal Cycling Exercise. Tohoku J. Exp. Med., 2004, 202 (3), 203-211 — We studied the changes in urinary bicarbonate, urinary $\mathrm{pH}$ and some physical parameters such as minute ventilation $(\dot{\mathrm{V} E})$, oxygen consumption $\left(\dot{\mathrm{V}}_{2}\right)$, respiratory carbon dioxide $(\dot{\mathrm{V} C O})_{2}$, heart rate, blood pressure, and blood lactate, before and after the submaximal exercise. Six male subjects aged 28-33 years were involved in the study. They performed the incremental exercise test using a bicycle ergometer until exhaustion. Levels of $\dot{\mathrm{V}} \mathrm{E}, \dot{\mathrm{V}} \mathrm{O}_{2}, \dot{\mathrm{V}} \mathrm{CO}_{2}$, heart rate, and blood pressure increased continuously with an increase in cycling intensity. These parameters markedly decreased and reached the baseline levels within 5-10 minutes after the termination of exercise. According to an increase in cycling intensity, blood lactate increased continuously during exercise, but after termination of exercise the return of lactate to the baseline level was markedly retarded. Urinary bicarbonate and $\mathrm{pH}$ were within the range of those at 0 time (baseline levels) from the beginning until 30 minutes after the exercise. However, they began to increase abruptly about 30 minutes after the exercise, and continued to increase extensively for 2 hours thereafter. Such marked increase in urinary bicarbonate and $\mathrm{pH}$ seemed to be correlated with the aerobic metabolism of lactate in the muscles, liver, and kidney, finally producing $\mathrm{CO}_{2}$. It was also suggested that the measurement of urinary bicarbonate and $\mathrm{pH}$ may be useful for the estimation of physiological changes in the body after submaximal incremental cycling exercise loading. cycling exercise; acid-base balance; urinary $\mathrm{HCO}_{3}{ }^{-}$

(C) 2004 Tohoku University Medical Press

Received December 1, 2003; revision accepted for publication February 4, 2004.

Address for reprints: Akio Tomoda, M.D., Ph.D., Department of Biochemistry, Tokyo Medical University,

6-1-1 Shinjuku, Shinjuku-ku, Tokyo 160-8402, Japan.

e-mail: tomoda@tokyo-med.ac.jp 
It has been recognized that during exhaustive exercise both aerobic and anaerobic metabolisms are accelerated, the former causing the overproduction of carbon dioxide $\left(\mathrm{CO}_{2}\right)$, and the latter causing the accumulation of lactate in the blood. Excessive $\mathrm{CO}_{2}$ produced in the tissues involved in exhaustive exercise is excreted into blood where it is converted to bicarbonate $\left(\mathrm{HCO}_{3}{ }^{-}\right)$in the reactions with erythrocytic carbonic anhydrase $\left(\mathrm{CO}_{2}+\mathrm{H}_{2} \mathrm{O} \rightleftarrows \mathrm{H}_{2} \mathrm{CO}_{3} \rightleftarrows \mathrm{H}^{+}+\mathrm{HCO}_{3}{ }^{-}\right)$. Then, excessive $\mathrm{CO}_{2}$ is discharged into the expired air after the reverse reaction of $\mathrm{HCO}_{3}{ }^{-}$to $\mathrm{CO}_{2}$. Hyperpnea during heavy exercise may contribute to minimizing alterations in the arterial blood $\mathrm{pH}$ (Krogh and Lindhard 1913; Dejours 1964) by discharging excessively produced $\mathrm{CO}_{2}$. Satin and Åstrand (1967) also showed that $\mathrm{CO}_{2}$ in the expired air is markedly increased during exercise. During exhaustive exercise, $\mathrm{CO}_{2}$ produced in the tissues is regularly discharged from the body through such mechanisms. However, it is conceivable that if discharge of overproduced $\mathrm{CO}_{2}$ is prevented by the quick recovery of respiration to normal level, there is no way to discharge $\mathrm{CO}_{2}$ from the body other than converting it to $\mathrm{HCO}_{3}$ - and discharging $\mathrm{HCO}_{3}{ }^{-}$into the urine. Namely, large amounts of $\mathrm{HCO}_{3}{ }^{-}$, exceeding 24-28 mM, may be discharged into the urine (Pitts et al. 1949).

Stringer et al. (1992) studied the time-related changes in arterial blood $\mathrm{pH}$, arterial $\mathrm{PcO}_{2}$, arterial blood $\mathrm{HCO}_{3}{ }^{-}$, lactate, and minute ventilation after the start of heavy exercise by an ergometer cycling. They found that blood $\mathrm{HCO}_{3}{ }^{-}$is stoichiometrically decreased against the rapid increase of blood lactate, which releases corresponding amounts of hydrogen ion, and that according to the disappearance of lactate from the blood, the levels of blood $\mathrm{HCO}_{3}{ }^{-}$return to normal level during recovery period. However, since blood lactate levels were maintained still higher during the recovery period as indicated by Stringer et al. (1992), $\mathrm{CO}_{2}$ may be persistently released into the blood. Therefore, it will be crucial to study the fate of $\mathrm{CO}_{2}$ in the blood after sedation of ventila- tion which was caused by heavy exercise.

We previously showed that urinary bicarbonate and $\mathrm{pH}$ markedly increased immediately after locally loaded heavy muscular exercise with dynamic knee extension (Moriguchi et al. 2002a), and suggested that $\mathrm{CO}_{2}$ produced by the muscles involved in extreme submaximal loading exercise was converted to $\mathrm{HCO}_{3}{ }^{-}$in the blood. As a result, the excessive amount of $\mathrm{HCO}_{3}{ }^{-}$was discharged into urine because of rapid sedation of ventilation. Marked increase of urinary bicarbonate and $\mathrm{pH}$ means that the blood $\mathrm{pH}$ will become acidified by leftover hydrogen ion in the blood. This blood acidification may correlate with fatigue after heavy exercise (Moriguchi et al. 2002b). In spite of these facts, there are few reports on the changes in urinary $\mathrm{HCO}_{3}{ }^{-}$during and after systemic exercise because urinary $\mathrm{HCO}_{3}{ }^{-}$has usually been considered negligible, and urinary $\mathrm{pH}$ is around 5.5 (Pitts et al. 1949).

In this study, we investigated the changes in urinary $\mathrm{HCO}_{3}{ }^{-}$and $\mathrm{pH}$ related to blood lactate and other physiological parameters during and after submaximal bicycle erogometer exercise accompanying systemic exercise.

\section{Materials And Methods}

\section{Subjects}

Subjects were six healthy male volunteers (28-33 years old; height: $175.0 \pm 1.9 \mathrm{~cm}$, weight: $67.3 \pm 3.1 \mathrm{~kg}$, means \pm S.E). The study was performed at the laboratory of Department of Preventive Medicine and Public Health, Tokyo Medical University, on scheduled days in August, 2002. After obtaining written informed consent, urine samples and blood samples were collected at constant intervals according to the exercise program. Breathing was measured continuously, using Aeromonitor AE-280S (Minato Medical Science Co. Ltd., Osaka).

\section{Exercise protocol and exercise position}

An incremental exercise test was performed using a bicycle erogometer (Model-868: MONARK Co., Ltd., Varberg, Sweden). Subjects 
pedaled until complete exhaustion; the first step in the series consisted of 3 minutes exercise at a 30 Watt $(\mathrm{W})$ load $(0.5 \mathrm{kp} \times 60 \mathrm{rpm})$ followed by 1 minute of rest. The load was increased by 30 $\mathrm{W}$ increments for each subsequent step in the series until the subjects reached exhaustion. The resistance was increased incrementally, but the revolutions per minute were unchanged throughout. In order to isolate the muscle groups of the lower body that are most active during the cycling exercise, subjects performed the cycling exercise while lying on a bed in a supine position (Koga et al. 1999; Julien et al. 2002). Furthermore, as the body of subjects were supported by a bed, the influence of their weight on exercise movement could be eliminated.

The subjects were secured to the bed by a belt around the shoulders. Blood pressure was measured in the right arm, and blood samples were taken from a left fingertip. After the termination of exercise, the subjects rested in a bed in the supine position as described in a previous report (Pronk 1993)

On the scheduled day, each subject visited the laboratory at 8:30 a.m. and rested for 1 hour. At 9:30 a.m., they started the cycling exercise and continued it until exhaustion. During exercise, blood was drawn from the fingertips of the subjects, at 3 minute intervals. After reaching exhaustion, blood was drawn at 1, 5, 10, 20, 30, 40, 50, and 60 minutes. Expired gas, heart rate, and blood pressure were measured continuously until 60 minutes after the termination of exercise. Urine samples were collected at 9:25 (baseline), 10:30 (60 minutes), 11:30 (120 minutes), and $12: 30$ (180 minutes). On the day of the experiments, the subjects were given water to avoid dehydration and to ensure a sufficient volume of urine. They took $200 \mathrm{ml}$ distilled water at 9:30, 10:30 and 11:30.

\section{Measurement of urine samples}

Immediately after the excretion of urine into a $200 \mathrm{ml}$ paper cup, the urine sample was transferred via a syringe into a $5 \mathrm{ml}$ rubber-capped vacuum glass tube (Veno-ject; Terumo Co., Ltd., Tokyo). Urine samples in rubber-capped vacuum glass tubes were preserved in a refrigerator. Urinary $\mathrm{pH}, \mathrm{CO}_{2}$ and bicarbonate remain stable for more than 3 weeks (Tomoda et al. 1995); however, each sample was examined the next day after completion of exercise program. Urinary $\mathrm{pH}$ and bicarbonate were analyzed by a Hitachi 8800 automatic blood gas analyzer (Hitachi Co. Ltd., Tokyo). Urinary bicarbonate concentration was estimated by the correction of the value of bicarbonate that was determined automatically by the machine, as was described by Stemmer et al. (1986) and Oster et al. (1988).

Measurement of blood lactate, heart rate, blood pressure and expirated gas

Blood lactate was measured with a Lactate Pro (Arkray Inc., Kyoto) using an enzymatic method as described in a previous report (Shimojo et al. 1993). Heart rate (HR) was measured with a Heart Rate Monitor (Polar Electro Inc., Kempele, Finland). Expired gas analysis for minute ventilation $(\dot{\mathrm{V} E})$, oxygen consumption $\left(\dot{\mathrm{V}}_{2}\right)$, and respiratory carbon dioxide $\left(\dot{\mathrm{V}} \mathrm{CO}_{2}\right)$ was undertaken by an Aeromonitor AE-280S (Minato Medical Science Co. Ltd., Osaka). Mean blood pressure (MBP) was measured with a Finapress BP Monitor (Ohmeda Co. Ltd., Engelwood, CO, USA).

\section{Atmospheric $\mathrm{CO}_{2}$}

Since increased atmospheric $\mathrm{CO}_{2}$ influences the levels of urinary bicarbonate and $\mathrm{pH}$ in the human body (Tomoda et al. 1995, 1997), the level of atmospheric $\mathrm{CO}_{2}$ in the room where the exercise study was performed was measured by a portable $\mathrm{CO}_{2}$ meter (Fuji Electronics Co., Ltd., Tokyo) at 9:30, 10:30, 11:30 and 12:30 on the days of exercise study. It was shown that the level of atmospheric $\mathrm{CO}_{2}$ in the room was almost constant (in the range between $650 \mathrm{ppm}$ and 800 ppm). 


\section{Statistical analysis}

Statistical analysis was performed by paired student's t test and one-way analysis of variance (ANOVA) for the data in Figs. 1-3 in order to investigate the changes in 1) respiratory parameters, 2) circulatory parameters, and 3) urinary bicarbonate level and urinary $\mathrm{pH}$ over time for given resistance. A $p$-value less than 0.05 was considered to indicate a statistically significant difference. All values were given as means \pm S.E. All statistical analyses were performed by utilizing a commercially available software package (SPSS version 10.0J).

\section{Results}

The parameters such as the changes in $\dot{\mathrm{VE}}$, $\dot{\mathrm{V}} \mathrm{O}_{2}, \dot{\mathrm{V}} \mathrm{CO}_{2}$, blood lactate, MBP, and HR during incremental cycling exercise with different intensities (30 W to $210 \mathrm{~W}$ ) are shown in Fig.1. According to the increase of exercise intensities, these values extensively increased together. Three of 6 subjects stopped at $150 \mathrm{~W}$ loading and one subject stopped at $180 \mathrm{~W}$, due to exhaustion, but two of the six subjects continued their exercise up to $210 \mathrm{~W}$ loading. In each subject, parameters such as $\dot{\mathrm{VE}}, \dot{\mathrm{V}} \mathrm{O}_{2}, \dot{\mathrm{V}} \mathrm{CO}_{2}$ and blood lactate reached levels several times as much as the baseline before exhaustion. MBP and HR significant increased twice, almost three times, in each subject.

After the termination of exhaustive exercise, the values of $\dot{\mathrm{VE}}, \dot{\mathrm{V}} \mathrm{O}_{2}, \dot{\mathrm{V}} \mathrm{CO}_{2}, \mathrm{MBP}$, and HR returned to the baseline level, within 5-10 minutes in each subject during the recovery period (Fig. 2). However, blood lactate remained higher for 5 minuets after the termination of exhaustive exercise, and then began to decrease slowly. Gradual decrease of blood lactate continued for 60 minutes and returned to the baseline level, in every subject (Fig. 2).

The changes in urinary $\mathrm{HCO}_{3}{ }^{-}$and $\mathrm{pH}$ before and after the exhaustive exercise are shown in Fig. 3. There were few changes in these values within 30 minutes after exercise termination. However, urinary $\mathrm{HCO}_{3}{ }^{-}$and $\mathrm{pH}$ abruptly began
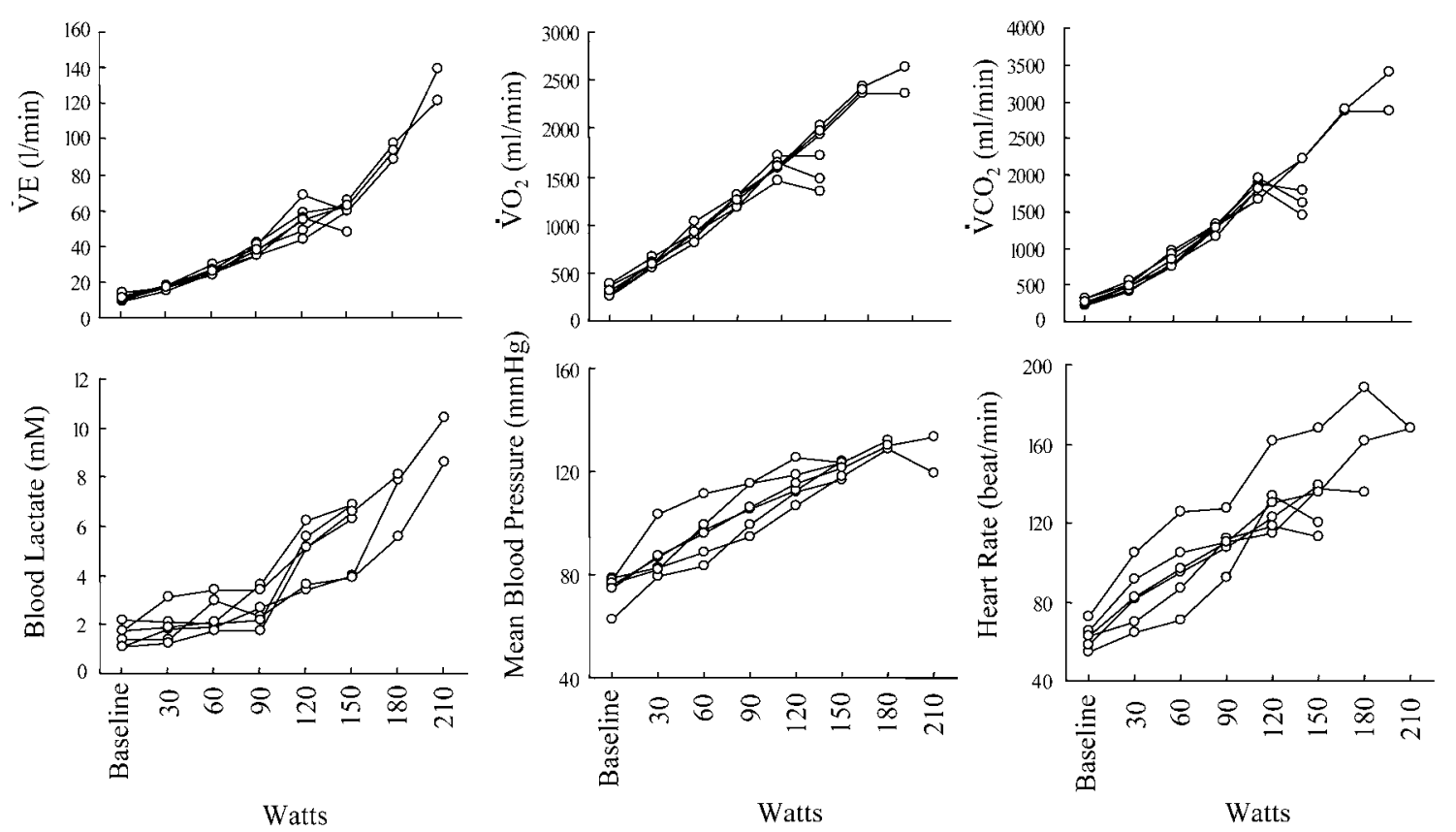

Fig. 1. Changes in minute ventilation $(\dot{\mathrm{V}} \mathrm{E})$, oxygen consumption $\left(\dot{\mathrm{V}} \mathrm{O}_{2}\right)$, respiratory $\mathrm{CO}_{2}\left(\dot{\mathrm{V}} \mathrm{VO}_{2}\right)$, blood lactate, mean blood pressure and heart rate during incremental cycling exercise with different intensities. The parameters including $\dot{\mathrm{V} E}, \dot{\mathrm{V}} \mathrm{O}_{2}, \dot{\mathrm{V}} \mathrm{CO}_{2}$, blood lactate, mean blood pressure and heart rate were measured for six subjects who performed incremental cycling exercise with different intensities $(30 \mathrm{~W}$ to $210 \mathrm{~W})$. 


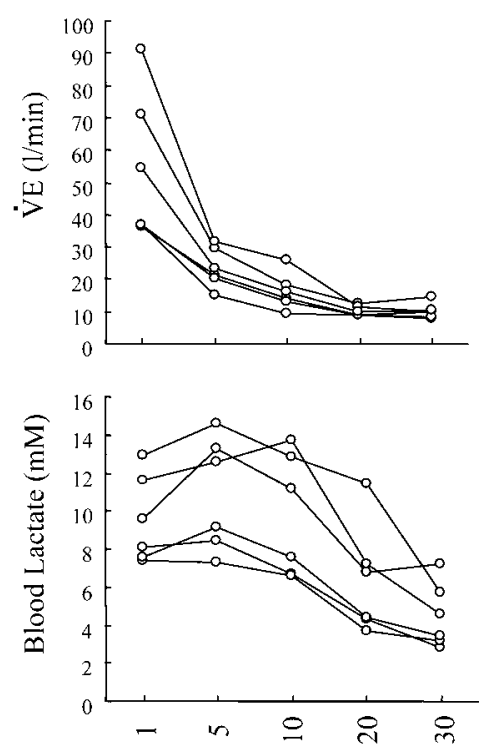

Recovery (minutes)
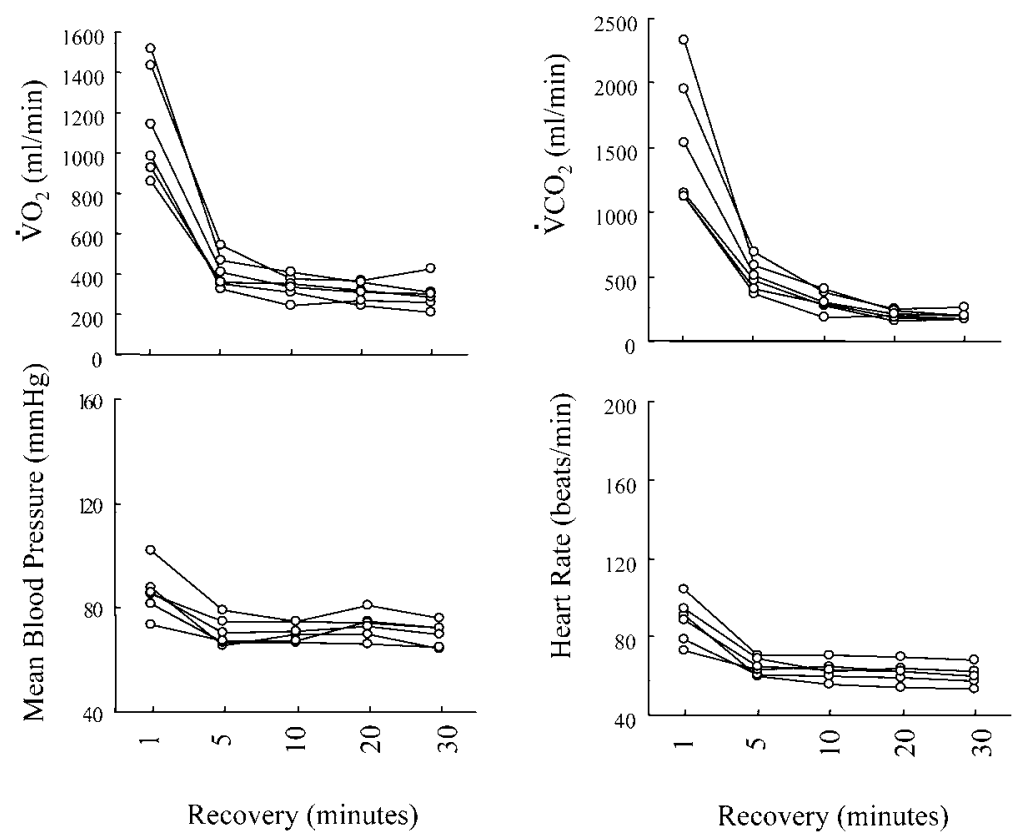

Recovery (minutes)

Fig. 2. Changes in minute ventilation $(\dot{\mathrm{V} E})$, oxygen consumption $\left(\dot{\mathrm{V}}_{2}\right)$, respiratory $\mathrm{CO}_{2}\left(\dot{\mathrm{V} C \mathrm{CO}_{2}}\right)$, blood lactate, mean blood pressure and heart rate after termination of incremental cycling exercise with different intensities. The changes in the parameters of each subject, after termination of the exercise were displayed for 30 minutes of the recovery period.

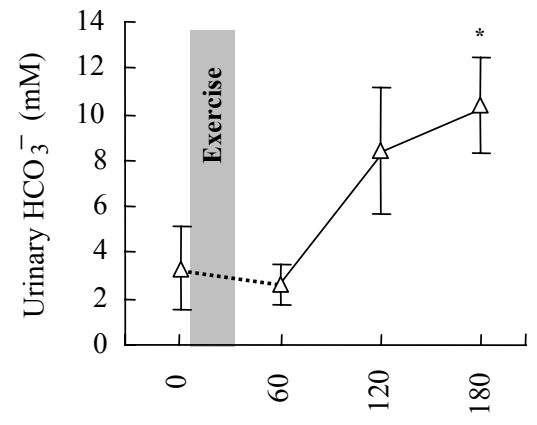

Minutes

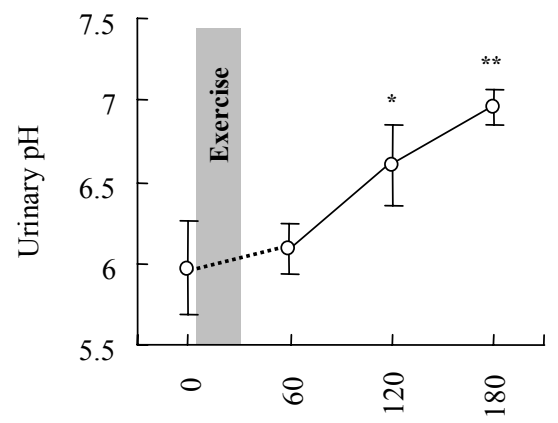

Minutes

Fig. 3. Urinary bicarbonate and $\mathrm{pH}$ before and after the termination of incremental and exhaustive cycling exercise. Urine samples were collected at 0 time (pre-exercise), and 30 minutes, 90 minutes and 150 minutes after the cessation of the exhaustive exercise, though the duration of the exercise of each subject differed. Baseline values were obtained immediately before the start of exercise. ${ }^{* * *} p<0.01,{ }^{*} p<0.05$ versus baseline values (ANOVA). Values are means \pm S.E.

to increase. These parameters increased markedly for 60 minutes (from $2.6 \mathrm{mM}$ to $10.4 \mathrm{mM}$, and from 6.2 to 7.0 , respectively), and continued to increase for another 60 minutes.

Fig. 4 illustrates the comparison of changes in blood lactate, $\dot{\mathrm{V}} \mathrm{O}_{2}, \dot{\mathrm{V}} \mathrm{CO}_{2}$ and urinary bicarbon- ate before and after incremental bicycle ergometer exercise. As mentioned above, $\dot{\mathrm{V}} \mathrm{O}_{2}, \dot{\mathrm{V}} \mathrm{CO}_{2}$, and blood lactate increased, but the levels of urinary bicarbonate did not change during the incremental exercise. After termination of the exercise due to exhaustion, $\dot{\mathrm{V}} \mathrm{O}_{2}$ and $\dot{\mathrm{V}} \mathrm{CO}_{2}$ decreased rapidly 


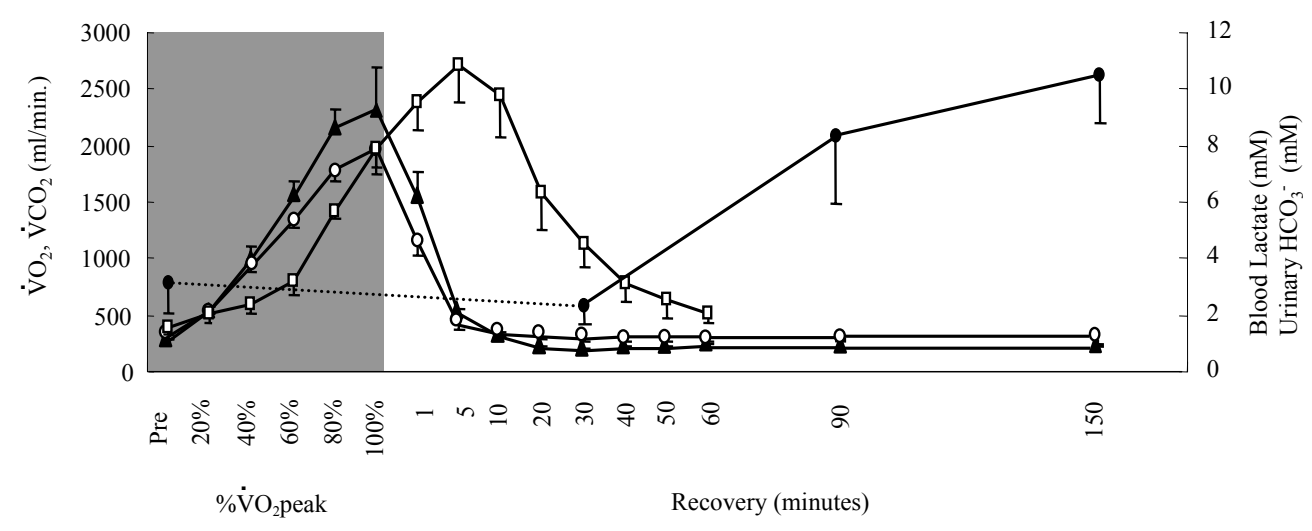

Fig. 4. Time course of the changes in $\dot{\mathrm{V}}_{2}(\bigcirc), \dot{\mathrm{V}}_{2}(\bullet)$, urinary bicarbonate $(\bullet)$, and blood lactate $(\square)$ before, during and after exercise. Values are means \pm s.E.

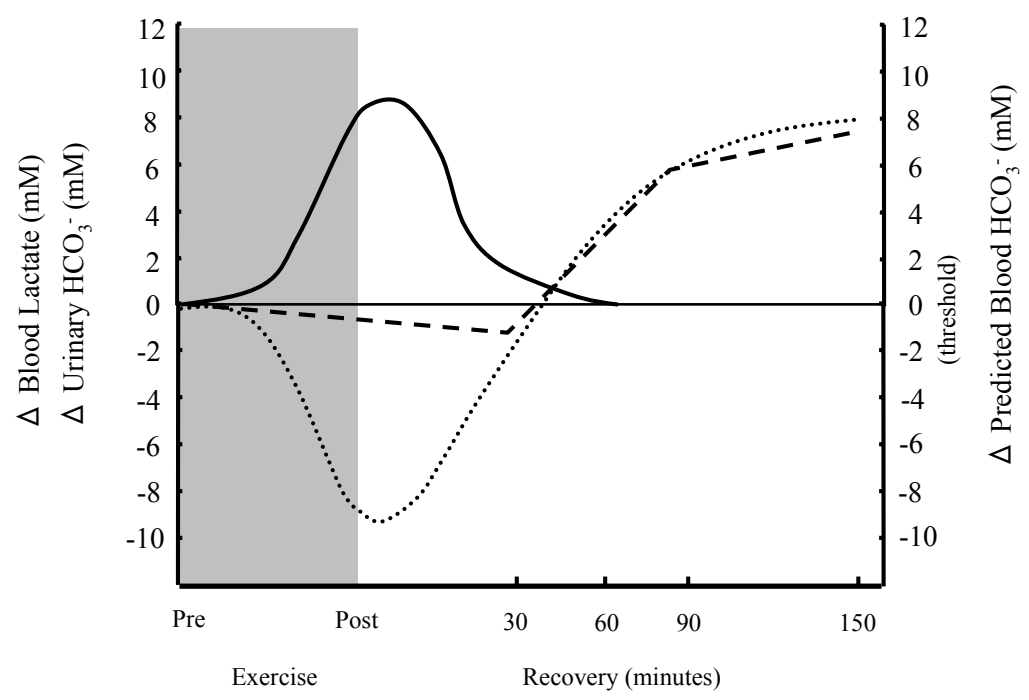

Fig. 5. Postulated changes in blood bicarbonate during the entire exercise period calculated from blood lactate and urinary bicarbonate. ——, $\Delta$ lactate in the blood during the entire exercise period; ,$---- \Delta$ urinary bicarbonate during the entire exercise period;....---- , predicted changes in blood bicarbonate during the entire exercise.

within 5-10 minutes, but the levels of blood lactate increased for 5 minutes. Thereafter, blood lactate began to decrease gradually for $60 \mathrm{~min}$ utes. On the contrary, urinary bicarbonate and $\mathrm{pH}$ did not alter even 30 minutes after the termination of the exercise. Then, they began to increase abruptly and continued to increase for more than 120 minutes to extensive levels.

\section{Discussion}

The fate of volatile $\mathrm{CO}_{2}$ in the blood is oriented to two pathways in humans, one pathway is direct discharge by expiration from the lung, and another is hydration by erythrocytic carbonic anhydrase toward bicarbonate and $\mathrm{H}^{+}$via carbonate $\left(\mathrm{CO}_{2}+\mathrm{H}_{2} \mathrm{O} \rightleftarrows \mathrm{H}_{2} \mathrm{CO}_{3} \rightleftarrows \mathrm{H}^{+}+\mathrm{HCO}_{3}{ }^{-}\right)$. When a higher concentration of ambient $\mathrm{CO}_{2}$ is inspired, blood $\mathrm{CO}_{2}$ will inevitably be changed to $\mathrm{HCO}_{3}{ }^{-}$ and $\mathrm{H}^{+}$via carbonate. In this case, excessively 
produced bicarbonate will be discharged into the urine because the threshold of blood bicarbonate is strictly maintained at $24-28 \mathrm{mM}$. Bicarbonate exceeding these values is shown to be overflown into the urine (Pitts et al. 1949). However, there are few detailed studies of the changes in urinary bicarbonate in normal subjects exposed to higher concentrations of ambient $\mathrm{CO}_{2}$. This is probably due to the fact that the level of urinary bicarbonate has been believed to be negligible in normal subjects (Pitts et al. 1949). Pitts et al. (1949) indicated that the excretion of titrable acid into urine decreases according to the increase of discharged amounts of bicarbonate into the urine from the blood, which is consistent with the view that during hypercapnea, bicarbonate will accumulate in the blood, resulting in discharge of bicarbonate into the urine and leftover hydrogen ion in the blood; thereby, causing acute respiratory acidosis. In 1990, Tomoda et al. $(1995,1997)$ reported that a large amount of bicarbonate was discharged into the urine accompanying the urinary alkalization in subjects who were confined to enclosed rooms or cars with closed windows and who inspired higher concentrations of $\mathrm{CO}_{2}$ for 3 hours or so. This result was explained by the fact that the increased $\mathrm{CO}_{2}$ in the blood was converted to bicarbonate and hydrogen ion by erythrocytic carbonic anhydrase, and the excessively produced bicarbonate was discharged into the urine. In this case, it was deduced that acidification of the blood will occur simultaneously because of the remaining $\mathrm{H}^{+}$in the blood. This view is consistent with the results of Shaeffer et al. (1963) and Pingree (1977) that respiratory acidosis was rapidly induced in normal subjects who were exposed to higher concentrations of $\mathrm{CO}_{2}$ (approximately $1 \% \mathrm{CO}_{2}$ ).

An obligate increase in bicarbonate in the blood will be caused by the increase of endogeneously produced $\mathrm{CO}_{2}$. During heavy exercise, $\mathrm{CO}_{2}$ production is accelerated in the human body due to the increase of aerobic and anaerobic metabolisms. Excessive $\mathrm{CO}_{2}$ is easily discharged into the expired air because ventilation is accelerated (Fig.1). In this study, bicarbonate in the blood is shown to be decreased in a stoichiometric manner to buffer the increased hydrogen ion caused by the production of lactate (Stringer et al. 1992). During the resting period after exercise, the ventilation returns to normal level within a few minutes. However, $\mathrm{CO}_{2}$ still continues to be produced because lactate accumulated in the blood during the exercise is shown to have been absorbed and metabolized in the muscle, liver and kidney (Hatta et al. 1988, 1989; Van 2000). As a result, excessive $\mathrm{CO}_{2}$ is released into the blood from these organs after constant time-lag. Because extensive amounts of $\mathrm{CO}_{2}$ cannot be discharged by expiration due to normal ventilation, it is eventually converted to bicarbonate and hydrogen ion by means of erythrocytic carbonic anhydrase. Bicarbonate, therefore, gradually returns to normal levels from the decreased state in the blood 30 minutes after the cessation of the heavy exercise, as Stringer et al. (1992) showed. Bicarbonate accumulates persistently after the recovery to normal levels in the blood, and will finally exceed the threshold value of $24-28 \mathrm{mM}$, when $\mathrm{CO}_{2}$ is progressively produced from lactate in the muscle and liver, at constant intervals after the cessation of the exercise. Bicarbonate will then be discharged into the urine. Our results showed that urinary bicarbonate began to abruptly increase about 30 minutes after the cessation of heavy systemic exercise and continued to increase to extensive levels (Figs. 3 and 4).

We estimated the possible changes in bicarbonate in the blood for the entire period before, during and after the exercise (Fig. 5), taking into account that the stoichiometric amount of bicarbonate is decreased in the blood in order to balance with blood lactate, as demonstrated by Stringer et al. (1992), and that the amount of urinary bicarbonate is equal to excessive bicarbonate in the blood over the threshold values of 24-28 $\mathrm{mM}$. We postulated that approximately $60 \%$ of blood lactate was oxidized completely to $\mathrm{CO}_{2}$ in the muscle, liver and kidney as was suggested by Hatta (1988, 1989), yielding 3 mols $\mathrm{CO}_{2}$ from 1 mol lactate. Since increased amount of blood lac- 
tate was $9.8 \mathrm{mM}$, we assumed that $17.6 \mathrm{mM} \mathrm{CO}_{2}$ was produced by complete oxidation of lactate $(9.8 \mathrm{mM} \times 0.6 \times 3=17.6 \mathrm{mM})$ and was converted to the equivalent amount of bicarbonate in the blood (dotted line in the figure). The stoichiometric amount of blood bicarbonate to balance with hydrogen ion derived from lactate (Stringer et al. 1992) will be $9.8 \mathrm{mM}$ during heavy exercise, because $\Delta$ blood lactate during exercise was $9.8 \mathrm{mM}$ (straight line in the figure). Thus, we can expect that $7.8 \mathrm{mM}(17.6-9.8=7.8)$ bicarbonate will be excessive in the blood, and will be discharged in the urine after the cessation of exercise. This calculation is consistent with the result that about $8 \mathrm{mM}$ urinary bicarbonate (broken line in the figure) was detected 120 minutes after the cessation of heavy exercise.

The present results suggest that the measurement of urinary bicarbonate and urinary $\mathrm{pH}$ will be useful to evaluate the acid-base balance in subjects exposed to high concentrations of atmospheric $\mathrm{CO}_{2}$ (Tomoda et al. 1995, 1997), or with increased amounts of endogeneous $\mathrm{CO}_{2}$ in the blood after heavy exercise such as submaximal cycling exercise.

\section{Conclusion}

The present report may be the first to confirm the marked increase in urinary bicarbonate $\left(\mathrm{HCO}_{3}\right.$ ${ }^{-}$) and urinary $\mathrm{pH}$ at the recovery period after exhaustive cycling exercise. Cycling exercise caused the excessive production of blood lactate exceeding more than $10 \mathrm{mM}$, which remained high, though it was consumed gradually in the recovery period after the termination of exercise. It was considered that the marked increase in urinary bicarbonate and urinary $\mathrm{pH}$ may be caused by conversion of lactate to $\mathrm{CO}_{2}$, resulting in $\mathrm{H}^{+}$ accumulation in the blood after the termination of exercise. Since urinary bicarbonate and $\mathrm{pH}$ seem to reflect the level of bicarbonate and hydrogen ion in the blood, these parameters will be useful for the evaluation of acid-base balance and energy metabolism in the human body during exercise and post-exercise periods.

\section{Acknowledgments}

The authors are grateful to Prof. J. Patrick Barron of the International Medical Communication Center, Tokyo Medical University, Tokyo, 160-0023, Japan for his review of the English manuscript. The present study was supported by a Grant-in-Aid for Scientific Research from the Ministry of Education, Science, Sports, and Culture of Japan (Grant no. 15500458, 2003).

\section{References}

Dejours, P. (1964) Control of respiration in muscular exercise. In: Handbook of Physiology, Respiration, Washington, D.C., Am. Physiol. Soc., 1, pp. 631-648.

Hatta, H., Atomi, Y., Yamamoto, Y., Shinohara, S. \& Yamada, S. (1988) Oxidation of lactate in rats after short-term strenuous exercise. Int. J. Sports Med., 9, 429-432.

Hatta, H., Atomi, Y., Yamamoto, Y., Shinohara, S. \& Yamada, S. (1989) Incorporation of blood lactate and glucose into tissues in rats after shortterm strenuous exercise. Int. J. Sports Med., 10, 275-278.

Julien, B., Edward, B., Gary, H., Glen, P., Russell, W. \& Bruce, D. (2002) Handgrip contribution to lactate production and leg power during highintensity exercise. Med. Sci. Sport Exrec., 34, 1037-1040.

Koga, S., Shiojiri, T., Shibasaki, M., Kondo, N., Fukuba, Y. \& Barstow, T.J. (1999) Kinetics of oxygen uptake during supine and upright heavy exercise. J. Appl. Physiol., 87, 253-260.

Krogh, A. \& Lindhard, J. (1913) The regulation of respiration and circulation during the initial stages of muscular work. J. Physiol. Lond., 47, 112-136.

Moriguchi, T., Shimomitsu, T., Odagiri, Y., Fukuda, J., Hamano, K., Kawai, T. \& Tomoda, A. (2002a) Marked increase in urinary bicarbonate and $\mathrm{pH}$ caused by heavy muscular exercise with dynamic knee extension. Tohoku J. Exp. Med., 198, 31-39.

Moriguchi, T., Shimomitsu, T., Odagiri, Y., Ichimura, S., Fukuda, J. \& Tomoda, A. (2002b) Circadian changes in urinary bicarbonate, nitric oxide metabolites and $\mathrm{pH}$ in female player during handball camp involved in an exercise, rest and sleep cycle. Tohoku J. Exp. Med., 196, 281-291.

Oster, J.R., Lopez, R., Peres, G.O., Alpert, H.A., Al- 
Reshaid, K.A.M. \& Vaamonde, C.A. (1988) The stability of $\mathrm{pH}, \mathrm{PcO}$, and calculated $\left[\mathrm{HCO}_{3}\right]$ of urine samples collected under oil. Nephron, 50, 320-324.

Pingree, B.J.W. (1977) Acid-base and respiratory change after prolonged exposure to $1 \%$ carbon dioxide. Clin. Sci. Mol. Med., 52, 67-74.

Pitts, R.F., Ayer, J.L. \& Schiess, W.A. (1949) The renal regulation of acid-base balance in man. The reabsorption and excretion of bicarbonate. $J$. Clin. Invest., 28, 35-43.

Pronk, N.P. (1993) Short term effects of exercise on plasma lipids and lipoproteins in humans. Sports Med., 16, 431-448.

Saltin, B. \& Åstrand, P.O. (1967) Maximal oxygen uptake in athletes. J. Appl. Physiol., 23, 353-358.

Schaeffer, K.E., Hastings, B.J., Carey, C.R. \& Nichols, G., Jr. (1963) Respiratory acclimatization to carbon dioxide. J. Appl. Physiol., 18, 1071-1078.

Shimojo, N., Naka, K., Uenoyama, H., Hamamoto, K., Yoshioka, K. \& Okuda, K. (1993) Electrochemical assay system with single-sue electrode strip for measuring lactate in whole blood. Clin. Chem., 39, 2312-2314.

Stemmer, C.L., Oster, J.R., Vaamonde, C.A., Perez, G.O. \& Rogers, A.I. (1986) The effect of routine doses of antacids on renal acidification. Lancet, 2, 3-6.

Stringer, W., Casaburi, R. \& Wasserman, K. (1992) Acid-base regulation during exercise and recovery in humans. J. Physiol., 954-961.

Tomoda, A., Yamanaka, S., Kawai, H., Ito, H., Katsumata, M., Minami, M., Hashimoto, T., Tanii, H. \& Hashimoto, K. (1995) Variation of urinary $\mathrm{pH}$ and bicarbonate concentrations of students in metropolitan and rural areas of Japan. Arch. Environ. Health, 50, 457-461.

Tomoda, A., Kazuka, M., Yashima, K., Niiyama, K. \& Muro, D. (1997) Significance of rises in urinary bicarbonate contents and $\mathrm{pH}$ related with increased atmospheric carbon dioxide in Tokyo. Tohoku J. Exp. Med., 183, 67-73.

Van, H.G. (2000) Lactate as a fuel for mitochondrial respiration. Acta Physiol. Scand., 168, 643-656. 